\title{
Effect of Nigella sativa on Estradiol Levels and Menopausal Symptoms in Post-Menopausal Females
}

${ }^{1}$ Shazo Sana, ${ }^{2}$ Hafiz Muhammad Umair, ${ }^{3}$ Muniza Saeed

${ }^{1}$ Department of Physiology, Fatima Jinnah Medical University, Lahore

${ }^{2}$ Department of Hematology, Fatima Jinnah Medical University, Lahore

${ }^{3}$ Department of Physiology, Postgraduate Medical Institute, Lahore

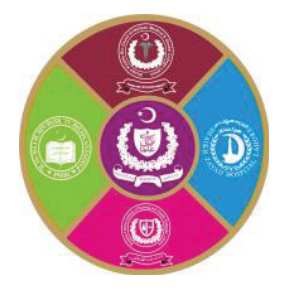

\begin{abstract}
Introduction: Menopause is the permanent cessation of menses, typically occurs in women of 45-55 years. Menopause is associated with a number of somatic, psychological and sexual symptoms due to decline in estradiol levels resulting in poor quality of life of postmenopausal females.

Aims \& Objectives: The purpose of the current study was to determine the effect of Nigella sativa on menopausal symptoms and estradiol levels in postmenopausal females.

Place and duration of study: Department of Physiology PGMI, Lahore for 8 weeks.

Material \& Methods: It was an interventional study conducted on 30 postmenopausal females. Nigella sativa was administered in the dose of $1 \mathrm{~g}$ /day after breakfast for a period of 8 weeks. Menopausal Rating Scale (MRS) was filled and blood sample was taken before and after giving Nigella sativa for estradiol and testosterone levels. Data was analyzed by paired t-test using SPSS- 21 and p- value less than 0.05 was considered significant.

Results: The result of the study showed that there was statistically significant reduction in the overall score of MRS ( $p=$ $0.001)$ and in all its domains, somatic $(p=0.001)$, psychological $(p=0.001)$ and urogenital $(p=0.017)$. There was also significant improvement in blood estradiol level after 8 weeks of Nigella sativa administration $(\mathrm{p}=0.021)$.

Conclusion: Nigella sativa supplementation increases estradiol level and decreases menopausal symptoms severity as indicted by significant reduction in the 3 domains of MRS and may be used by postmenopausal females on regular basis to improve their quality of life.
\end{abstract}

Key words: Nigella sativa, menopausal symptoms, estradiol level.

\section{INTRODUCTION}

$\mathrm{M}$ and recognized by absence of menstrual cycle for at least 1year typically in women of $45-55$ years. ${ }^{1}$ Two important hormones, estrogen and progesterone diminishes during menopause ${ }^{2}$ and results in various postmenopausal symptoms that are hot flushes especially in form of night sweats, mood fluctuation, generalized body fatigue and pains, dryness and atrophy of vagina resulting into poor quality of life of postmenopausal females. ${ }^{3}$ Menopausal Rating Scale (MRS) is a scale used for assessing the severity of menopausal symptoms in females. MRS is subdivided into 3 categories for assessment of 11 items i.e. somatic, psychological and urogenital symptoms. As the MRS score increases, the severity of symptoms also increases that negatively affect the quality of life of menopausal females. ${ }^{4,5}$ Nigella sativa (Kalonji) is a well-known medicinal plant with strong religious and historical background. Nigella sativa has been extensively studied for its biological activities and therapeutic properties i.e as anticancer, antihypertensive and antidiabetic, pain killer, antidiarrheal and many more. ${ }^{6}$ Research has shown that volatile oil of Nigella sativa contains significant amount of sex hormones like estradiol (278.56 $\mathrm{pg} / \mathrm{ml})$, progesterone $(5.55 \mathrm{ng} / \mathrm{ml})$, prolactin $(<0.5$ $\mathrm{ng} / \mathrm{ml})$ and testosterone $(1.8 \mathrm{ng} / \mathrm{ml}){ }^{7}$ More over Nigella sativa has estrogen like effects on uterine endometrium and on vaginal cells, as has been shown by the study conducted in ovarectimized female rats. ${ }^{8}$ Thus regular use of Nigella sativa may increase estradiol levels, decrease severity of menopausal symptoms and improve the lives of postmenopausal females.

\section{MATERIAL AND METHODS}

It was a Interventional study approved by IRB of Postgraduate Medical Institute Lahore vide (letter No. 3-IRB-14PGMI, dated: 14-05-2014) conducted on 30 Post-menopausal females. 


\section{Inclusion Criteria:}

- Females of age range 45-55 years having $\mathrm{BMI} \leq 30 \mathrm{~kg} / \mathrm{m}^{2}$

- Post-menopausal for duration of not more than 2 years.

\section{Exclusion Criteria:}

- Post-menopausal females taking hormonal replacement therapy (HRT), herbal medications like phytoestrogens and antioxidants like vitamin $\mathrm{E}$ and vitamin $\mathrm{C}$.

\section{Preparation of Nigella sativa capsules}

Nigella sativa seeds of good quality were purchased from local market. Seeds were ground in electric grinder until converted into fine powder that is then placed in empty capsules $(500 \mathrm{mg}) /$ capsule. Capsules were stored at room temperature in glass bottle with 60 capsules/ bottle.

Procedure: All subjects were informed about the research and consent was taken on consent proforma. History was taken and general physical examination was done and recorded on record proforma. Menopausal rating scale was filled before treatment with Nigella sativa by the researcher. Blood sample $(5 \mathrm{ml})$ was taken for pretreatment serum estradiol and testosterone levels. Serum was collected after centrifuging the blood at 3,000 rpm for $20 \mathrm{~min}$ at $25^{\circ} \mathrm{C}$ room temperature and stored at $20^{\circ} \mathrm{C}$. Subjects were asked to take 2 capsules of Nigella sativa $(1 \mathrm{~g})$ once a day after breakfast for a period of 8 weeks. ${ }^{9}$

Every subject was given a tabulated compliance sheet to write 'yes' after taking daily dose and reviewed during follow up visit fortnightly. After 8 weeks period of treatment, again blood sampling was done for post treatment estradiol and testosterone levels.

Serum estradiol level was estimated by estradiol enzyme immunoassay test kit having catalog number: 11110 manufactured by Oxis International, Inc 323 Vintage Park Dr. Foster City, CA 94404.

Testosterone Assay: Serum testosterone was estimated by testosterone ELISA kit. Catalog number: 1559 manufactured by Demeditec Diagnostics (Germany).

\section{Statistical analysis:}

SPSS version 21 was used to enter and analyze the data. The mean \pm S.D. was calculated for quantitative data and paired t-test was used to compare the pre and post treatment means of estradiol level. For comparing median IQR values of serum testosterone, Wilcoxin rank sum test was applied. p- value of $<0.05$ was considered statistically significant. Effect size was calculated by using Cohen's $\mathrm{d}$ test. Cohen's $\mathrm{d}=\Delta$ mean $/$ S.D. interpretation of Cohen's $d$ test is as; small sized effect $=0.2$, effect of moderate size $=$ up to 0.5 , effect of large size $=0.8$ and more. ${ }^{10}$

\section{RESULTS}

Healthy postmenopausal females $(n=30)$ were selected as study population. Females were not suffering from diabetes, hypertension and other medical disorders. They were taking no medications including multivitamins. The general characteristics are presented in Table-1.

\begin{tabular}{|c|c|}
\hline Parameters & Mean \pm S.D. \\
\hline Age (Years) & $49.9 \pm 3.16$ \\
\hline Years being post menopause & $1.76 \pm 0.44$ \\
\hline Pulse (per min) & $82,76.4-86.2^{*}$ \\
\hline Systolic BP $(\mathrm{mmHg})$ & $142.6 \pm 5.4$ \\
\hline Diastolic BP $(\mathrm{mmHg})$ & $88.7 \pm 10.38$ \\
\hline BMI $(\mathrm{kg} / \mathrm{m} 2)$ & $25.2,23.4-27.1^{*}$ \\
\hline
\end{tabular}

Table-1: General characteristics of the study population

Estradiol levels: Paired t-test was used to compare the pre and post treatment mean serum estradiol levels. The analysis result showed statistically significant increase in serum estradiol levels $(\mathrm{p}=$ 0.022 ) as shown in Table-2.

Testosterone levels: The Wilcoxin rank sum test was used for comparison of pre and post treatment median (IQR) of testosterone levels, the analysis showed that there was statistically non-significant increase in the testosterone level $(p=0.167)$ as depicted in Table-2.

Estradiol/Testosterone ratio (E/T): The pre and post treatment mean $\mathrm{E} / \mathrm{T}$ ratios were analyzed by paired $t$ - test and the result indicated a nonsignificant increase $(\mathrm{p}=0.344)$ as given in Table-2.

\begin{tabular}{|l|c|c|c|}
\hline Parameters & $\begin{array}{c}\text { Before } \\
\text { treatment }\end{array}$ & $\begin{array}{c}\text { After } \\
\text { treatment }\end{array}$ & P-value \\
\hline $\begin{array}{l}\boldsymbol{\Delta} \text { Estradiol level } \\
\text { (pg/ml) mean } \pm \text { S.D. }\end{array}$ & $10.33 \pm 2.909$ & $11.32 \pm 3.48$ & $0.021^{*}$ \\
\hline $\begin{array}{l}\text { Testosterone level } \\
(\mathrm{ng} / \mathrm{ml}) \text { median (IQR) }\end{array}$ & $\begin{array}{c}1.38, \\
1.196-1.674\end{array}$ & $\begin{array}{c}1.58, \\
1.186-1.722\end{array}$ & 0.174 \\
\hline $\begin{array}{l}\boldsymbol{\Delta} \text { Estradiol } \\
\text { Testosterone Ratio } \\
(\text { E/T) mean } \pm \text { S.D. }\end{array}$ & $6.72 \pm 1.45$ & $6.98 \pm 1.27$ & 0.353 \\
\hline
\end{tabular}

*significant. $\boldsymbol{\Delta}$ analyzed by paired t- test ${ }^{\text {analyzed by }}$ wilcoxson rank sum test

Table-2: Comparison of sex hormones of postmenopausal women before and after consumption of Nigella sativa for 8 weeks 
For the assessment of the severity of menopausal symptoms, menopausal rating scale was used. The most frequently reported symptoms include hot flushes $(77.3 \%)$, generalized body aches and pain $(54.7 \%)$, anxiety $(53.3 \%)$ followed by depressive mood (49.6\%), bladder symptoms $(26.6 \%)$ and sexual problems (19.9\%) as given in Table-3.

\begin{tabular}{|c|c|c|c|c|}
\hline MRS & $\begin{array}{c}\text { Mild } \\
\text { No. (\%) }\end{array}$ & $\begin{array}{l}\text { Moderate } \\
\text { No. (\%) }\end{array}$ & $\begin{array}{l}\text { Severe } \\
\text { No. }(\%)\end{array}$ & $\begin{array}{c}\text { Total } \\
\%\end{array}$ \\
\hline \multicolumn{5}{|c|}{ Somatic } \\
\hline $\begin{array}{l}\text { Hot flushes } \\
(n=23)\end{array}$ & $12(40.7)$ & $7(23.3)$ & $4(13.3)$ & $77.3 \%$ \\
\hline $\begin{array}{l}\text { Heart discomfort } \\
\quad(\mathrm{n}=15)\end{array}$ & $9(29.7)$ & $5(16.7)$ & $1(3.3)$ & $49.7 \%$ \\
\hline $\begin{array}{c}\text { Sleep problems } \\
(\mathrm{n}=10)\end{array}$ & $7(23.3)$ & $2(6.6)$ & $1(3.3)$ & $33.2 \%$ \\
\hline $\begin{array}{c}\text { Joint muscular } \\
\text { discomfort }(\mathrm{n}=16)\end{array}$ & $5(16.7)$ & $6(20.3)$ & $5(16.7)$ & $53.7 \%$ \\
\hline \multicolumn{5}{|c|}{ Psychological } \\
\hline $\begin{array}{c}\text { Depressive mood } \\
(\mathrm{n}=13)\end{array}$ & $9(29.7)$ & $4(13.3)$ & $2(6.6)$ & $49.6 \%$ \\
\hline $\begin{array}{c}\text { Irritability } \\
(\mathrm{n}=8)\end{array}$ & $5(16.7)$ & $2(6.6)$ & $1(3.3)$ & $26.6 \%$ \\
\hline $\begin{array}{c}\text { Anxiety } \\
(\mathrm{n}=16)\end{array}$ & $10(33.3)$ & $5(16.7)$ & $1(3.3)$ & $53.3 \%$ \\
\hline $\begin{array}{l}\text { Physical \& mental } \\
\text { exhaustion }(\mathrm{n}=17)\end{array}$ & $7(23.3)$ & $4(13.3)$ & $2(6.6)$ & $43.2 \%$ \\
\hline \multicolumn{5}{|c|}{ Urogenital } \\
\hline $\begin{array}{l}\text { Sexual problems } \\
\qquad(\mathrm{n}=6)\end{array}$ & $5(16.6)$ & $1(3.3)$ & $0(0)$ & $19.9 \%$ \\
\hline $\begin{array}{c}\text { Bladder problems } \\
(\mathrm{n}=8)\end{array}$ & $5(16.7)$ & $2(6.6)$ & $1(3.3)$ & $26.6 \%$ \\
\hline $\begin{array}{c}\text { Dryness of } \\
\text { vagina }(n=6)\end{array}$ & $4(13.3)$ & $2(6.6)$ & $0(0)$ & $19.9 \%$ \\
\hline
\end{tabular}

$\mathrm{n}=$ no. of subjects having symptoms

Table-3: Frequency distribution of Menopausal Rating Scales (MRS) of the study population

The pretreatment mean score of MRS was $14.7 \pm 5.7$, somatic domain 7.7 \pm 3.7 , psychological domain $5.53 \pm 3.12$ and of urogenital domain was $2.93 \pm 1.4$. After consuming Nigella sativa for 8 weeks, paired $\mathrm{t}$ - test was applied for comparison of the pre and post treatment mean MRS and its domains. The result showed a statistically significant reduction in overall score of MRS $(p=0.001)$ and in somatic $(p$ $=0.001)$, psychological $(\mathrm{p}=0.001)$ and urogenital domain $(p=0.019)$ as given in Fig-1.

Effect size was calculated by cohen's d formula for menopausal symptom scores and biochemical parameters and given in Table- 4 .

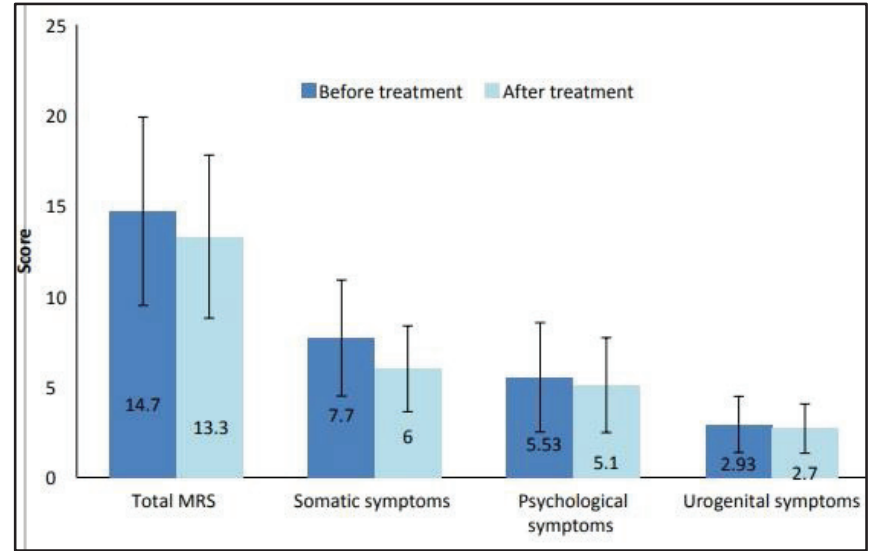

Fig-1: Changes in the domains of MRS score after 8week consumption of Nigella sativa.

\begin{tabular}{|c|c|}
\hline Parameters & Effect size \\
\hline Estradiol level & $0.3 * * *$ \\
\hline Testosterone level & $0.25 * * *$ \\
\hline E/T & $0.17 * * *$ \\
\hline MRS score & $-0.27 * * *$ \\
\hline Somatic symptoms score & $-0.53 * *$ \\
\hline Psychological symptoms score & $-0.14 * * *$ \\
\hline Urogenital symptoms score & $-0.14 * * *$ \\
\hline
\end{tabular}

Table-4: Effect size of change in biochemical parameters after Nigella sativa consumption

*large effect size $(\geq 0.8)$

**moderate effect size (up to 0.5 )

$* * *$ small effect size (up to 0.2 )

\section{DISCUSSION}

Menopause denotes reproductive aging in females, resulting in decline in the estradiol levels gradually. ${ }^{11}$ This decrease in estradiol level causes various menopausal symptoms such as vasomotor symptoms, osteoporosis and heart diseases. ${ }^{12}$ The present study was conducted to show the effect of Nigella sativa on sex hormones i-e., estradiol level, testosterone level and estradiol testosterone ratio $(\mathrm{E} / \mathrm{T})$. There is statistically significant improvement $(\mathrm{P}=0.022)(\mathrm{ES}=0.3)$ in the estradiol levels after 8 weeks' treatment of Nigella sativa. This finding is in line to the study of Perhizkar et. al. 2011 on ovarectimized rats that Nigella sativa has estrogen like effects on uterine endometrium and vaginal cells. ${ }^{8}$ In 2016, Parhizkar et. al. again showed that Nigella sativa has uterotrophic activities on endometrial changes and cornification of vaginal cells in rats as well as it raises blood estradiol levels. ${ }^{13}$ This uterotrophic property of Nigella sativa was initially thought to be because of its phenolic and flavonoid contents having estrogenic activities ${ }^{14}$ but research also showed presence of different types of sex hormones like estradiol, progesterone, prolactin and testosterone in substantial amounts. ${ }^{7}$ 
The current study also showed that Nigella sativa improved testosterone levels but difference is not significant statistically $(\mathrm{P}=0.174)(\mathrm{ES}=0.25)$. This is similar to the findings of Datau et. al. (2010) that serum testosterone level did not raise significantly after consuming $3 \mathrm{~g}$ of Nigella sativa /day in obese males for 3 months. ${ }^{15}$ However, another study contradicts our results by showing a significant increase in serum testosterone levels after 3 months' consumption of $300 \mathrm{mg} /$ body weight Nigella sativa in infertile males. ${ }^{16}$

In our study, Nigella sativa might have raised the serum testosterone level in postmenopausal females but that may have been converted into estradiol. As far as the estradiol / testosterone (E/T) is concerned, after 8-week consumption of Nigella sativa, there has been improvement in the $\mathrm{E} / \mathrm{T}$ ratio. Although the result is not significant $(\mathrm{P}=0.375)(\mathrm{ES}=0.17)$ but there is still an improvement which is indirectly related to the better health of the postmenopausal females as increased $\mathrm{E} / \mathrm{T}$ is a risk factor for heart diseases ${ }^{17}$ and metabolic syndrome. ${ }^{18}$ In the current study, MRS has been used for scoring the menopausal symptoms severity of study population. Administration of Nigella sativa improves psychological well-being and reduces the menopausal symptoms severity as shown by statistically significant reduction in overall score of MRS $(\mathrm{P}=0.001)(\mathrm{ES}=0.27)$. A significant decrease in symptoms of somatic domain $(\mathrm{P}=0.001)(\mathrm{ES}=$ $0.53)$, psychological domain $(\mathrm{P}=0.001)(\mathrm{ES}=0.14)$ and urogenital domain $(\mathrm{P}=0.017)(\mathrm{ES}=0.14)$ has been observed after Nigella sativa administration. This finding is in agreement with Perhizkar and Manzori who have done a randomized controlled trial in 2015 to see the effect of Nigella sativa on menopausal symptoms and improvement in the quality life of postmenopausal females. ${ }^{19}$ Their results showed that Nigella sativa significantly improved the menopausal symptoms and could be an alternative of Hormone replacement therapy (HRT).

\section{CONCLUSION}

Nigella sativa supplementation increases estradiol level and decreases menopausal symptoms as indicted by significant reduction in the 3 domains of MRS.

\section{Recommendation:}

1. We recommend that Nigella sativa may be used by postmenopausal females on regular basis to improve their quality of life.

2. A comparative interventional study should be done with comparison of Nigella sativa with
HRT for further proof of Nigella sativa being an alternative of HRT.

3. A study showing the long-term effects of the Nigella sativa supplementation should be considered along with periodic measurements of estradiol for several years to strengthen the efficacy of the Nigella sativa.

\section{REFERENCES}

1. Rosett JW. Menopause, micronutrients, and hormone therapy. Am J Clin Nutr. 2005; 81(5):1223-31.

2. Mendoza CCC, Zamarripa CAJ. Menopause Induces Oxidative Stress, [Internet]. [cited 2016 May 12]. Available from: http://dx.doi.org/10.5772/52082.

3. Rahman SA, Zainudin SR, Mun VL. Assessment of menopausal symptoms using modified Menopause Rating Scale (MRS) among middle age women in Kuching, Sarawak, Malaysia. Asia Pac Fam Med. 2010; 9:5.

4. Heinemann LA, Potthoff P, Schneider HPG. International versions of the Menopause Rating Scale (MRS). Health Qual Life Outcomes, 2003;1:28

5. Heinemann K, Ruebig A, Potthoff P, Schneider HP, Strelow F, Heinemann LA. The Menopause Rating Scale (MRS) scale: a methodological review. Health Qual Life Outcomes, 2004; 2:45.

6. Ahmed A, Husain A, Mujeeb M, Khan SA, Najmi AK, Siddique NA et.al. A review on therapeutic potential of Nigella sativa: A miracle herb. Asian Pac J Trop Biomed. 2013; 3(5): 337-52.

7. Altalee AH, Ewadh MJ, Zaidan HK. Hormonal Contents of Two Types of Black Seed (Nigella sativa) Oil: Comparative Study. M J B.2006; 3(1-2): 17-21.

8. Parhizkar S, Latiff LA, Rahman SA, Dollah MA, Parichehr H. Assessing estrogenic activity of Nigella sativa in ovariectomized rats using vaginal cornification assay. Afr J Pharm Pharmacol. 2011; 5(2):137- 42.

9. Ibrahim RM, Hamdan NS, Mahmud R, Imam MU, Saini SM, Rashid SN et.al. A randomized controlled trial on hypolipidemic effects of Nigella Sativa seeds powder in menopausal women. J Transl Med. 2014; 12:82.

10. Kirkwood BR, Sterne JAC. 2002. Essential Medical Statistics. 2nd ed., London, W.J. Elizebeth.

11. Carr, M.C., 2003. The Emergence of Metabolic Syndrome with Menopause. J Clin Endocrinol Metab, 88(6): 2404-2411.

12. Doshi, S.B. and Agrawal, A., 2013. The role of oxidative stress in menopause. J Midlife Health, 4(3): 140-146.

13. Parhizkar S, Abdul Latiff L, Parsa A. Effect of Nigella sativa on reproductive system in experimental menopause rat model. Avicenna J Phytomed. 2016; 6 (1): 95-103.

14. Mahmood RI. Physiological and histological effects of alcoholic and aqueous extract of Nigella sativa 
seed on fertility potential in male mice. J Genet Environ Resour Conserv, 2015; 3(2):138-144.

15. Datau EA, Wardhana Surachmanto EK, Pandelaki K, Langi JA, 2010. Efficacy of Nigella Sativa on Serum Free Testosterone and Metabolic Disturbances in Central Obese Male. Acta Med Indones-Indones J Intern Med. 42 (3): 130-134.

16. Haseena S, Aithal M, Das KK, Saheb SH. Effect of Nigella Sativa Seed Powder on Testosterone and LH levels in Sterptozotocin Induced Diabetes Male Albino Rats. J Pharm Sci \& Res. 2015; 7(4): 234-7.

17. Dai W, Li Y, Zheng H. Estradiol/Testosterone Imbalance: Impact on Coronary Heart Disease Risk Factors in Postmenopausal Women. Cardiology. 2012; 121:249-54.

18. Torrens JI, Sutton-Tyrrell K, Zhao X, Matthews K, Brockwell S, Sowers M, et. al. Santoro, N. Relative androgen excess during the menopausal transition predicts incident metabolic syndrome in mid-life women. Menopause. 2009; 16 (2): 257-64.

19. Parhizkar S, Leila Manzouri L. A randomized controlled trial on climacteric symptoms management and quality of life improvement of Nigella sativa seeds powder in menopausal women. [internet]. 2015 [ cited 2016 Sept 19] Available from:http://dx.doi.org/10.1016/j.maturitas.2015.02.232.

\section{The Authors:}

Dr. Shazo Sana

Demonstrator,

Department of Physiology,

Fatima Jinnah Medical University, Lahore.

Dr. Hafiz Muhammad Umair

Senior Demonstrator,

Department of Hematology,

Fatima Jinnah Medical University, Lahore.

Prof. Muniza Saeed

Head, Department of Physiology, Postgraduate Medical Institute, Lahore.

\section{Corresponding Author:}

Dr. Shazo Sana

Demonstrator, Department of Physiology, Fatima Jinnah Medical University, Lahore. E-mail: shazirose2011@hotmail.com 